\title{
Efficacy of Area-Wide Inoculum Reduction and Vector Control on Temporal Progress of Huanglongbing in Young Sweet Orange Plantings
}

\author{
Renato B. Bassanezi, Luiz H. Montesino, and Nelson Gimenes-Fernandes, Departamento Científico, Fundo de Defesa da Citricul- \\ tura, 14807-040, Araraquara, SP, Brazil; Pedro T. Yamamoto, Departamento de Entomologia e Acarologia, Escola Superior de Agricul- \\ tura Luiz de Queiroz, Universidade de São Paulo, 13418-900, Piracicaba, SP, Brazil; Tim R. Gottwald, United States Department of \\ Agriculture-Agricultural Research Service, USHRL, Fort Pierce, FL 34945; and Lilian Amorim and Armando Bergamin Filho, \\ Departamento de Fitopatologia e Nematologia, Escola Superior de Agricultura "Luiz de Queiroz", Universidade de São Paulo, 13418- \\ 900, Piracicaba, SP, Brazil
}

\begin{abstract}
Bassanezi, R. B., Montesino, L. H., Gimenes-Fernandes, N., Yamamoto, P. T., Gottwald, T. R., Amorim, L., and Bergamin Filho, A. 2013. Efficacy of area-wide inoculum reduction and vector control on temporal progress of huanglongbing in young sweet orange plantings. Plant Dis. 97:789796.

Huanglongbing (HLB), caused by 'Candidatus Liberibacter' spp. and transmitted by the Asian citrus psyllid Diaphorina citri (ACP), is an important threat to citrus industries worldwide, causing significant yield loss. The current recommended strategies to manage HLB are to eliminate HLB-symptomatic trees to reduce sources of bacterial inoculum and to apply insecticides to reduce psyllid vector populations. The objective of this study was to assess the effectiveness and the importance of both strategies applied within young citrus plots (local management), in different frequencies and combinations, on HLB temporal progress. Two factorial field experiments, E1 and E2, were initiated in a new plantation of sweet orange in an HLB epidemic region of Sao Paulo, Brazil, in October 2005 and May 2006, respectively. Local inoculum reduction (tree removal) intervals for E1 were every 4 , 8, and 16 weeks and, for E2, every 2, 4, 12, and 26 weeks. Local vector control strategies for E1 were no control, program A (PA), and program B (PB); and, for E2, no control and program C (PC), as follows. Psyllids were controlled with two 56-day-interval soil or drench applications of systemic insecticides concurrently with the rainy season

each year and, during the rest of the year, with insecticide sprays every 28 days for PA and every 14 days for PB and PC. Regional HLB management was present for E1 and absent for E2. The beginning of the HLB epidemic was delayed for 10 months in E1 compared with appearance of the first diseased tree in E2 but wasn't affected by different local strategies in either experiment. After 60 (E1) and 53 (E2) months, the HLB incidence and progress rates were not affected by different frequencies of local inoculum reduction in either experiment, and were different only in plots with and without local vector control in E2. In E1, the disease incidence was reduced by $90 \%$ and the disease progress rate by $50 \%$ in plots both with and without vector control. These reductions were explained by smaller psyllid populations and lower frequency of bacterialiferous psyllids in E1 compared with E2. Annual productivity increased over time in E1, as expected for young plantings, but remained stable or decreased in E2. These results confirm that immigration of bacterialiferous ACP vectors plays a critical role in HLB epidemics and suggest that area-wide inoculum reduction and ACP management strongly affect HLB control.
\end{abstract}

Citrus huanglongbing (HLB) is the most serious citrus disease worldwide and became a tremendous threat to the world citrus industry after its report in Sao Paulo (Brazil) and Florida (United States), the two largest citrus and juice producers $(5,11,14,15)$. In Brazil, where the disease was first detected in 2004, it is associated with two phloem-restricted bacterial species, 'Candidatus Liberibacter asiaticus' and ' $\mathrm{Ca}$. L. americanus' $(10,22)$, with a population shift from a predominance of ' $\mathrm{Ca}$. L. americanus' in 2004 to ' $\mathrm{Ca}$. L. asiaticus' since 2008 (20). Both species are spread in the field by the Asian citrus psyllid (ACP) Diaphorina citri Kuwayama (Hemiptera: Psyllidae) $(9,23)$.

Because all commercial citrus varieties and relatives are susceptible to HLB and there are no feasible and economic methods to cure HLB-infected trees, strategies to prevent as many trees as possible from becoming infected must be applied to manage HLB. Based on decades of experience of Asia's and South Africa's commercial producers and agricultural agencies, the prevention of HLB infection can only be achieved by (i) planting healthy nursery trees, (ii) eliminating pathogen inoculum by removing HLB-infected trees rapidly after detection, and (iii) keeping ACP populations as

Corresponding author: R. B. Bassanezi,

E-mail: rbbassanezi@fundecitrus.com.br

Accepted for publication 17 December 2012.

http://dx.doi.org/10.1094/PDIS-03-12-0314-RE

(c) 2013 The American Phytopathological Society low as possible by chemical or biological insecticides $(5,11,15)$. These recommended strategies have been used in the last 6 years in Sao Paulo and 5 years in Florida by the most diligent citrus growers in an attempt to suppress HLB progress, and these strategies will be employed until breeding for resistance to Liberibacter or $D$. citri provides a better solution for the HLB problem. According to empirical observations and the theory of plant disease management, the best HLB control would be achieved with frequent inoculum removal and a rigorous vector control program. However, the effectiveness and the importance of both recommended strategies on HLB temporal progress in the grove remain undefined, as are the optimum inspection and removal frequency and the minimum allowable psyllid vector populations. Until now, there has been no experiment that simultaneously examined the impacts of different frequencies of roguing and chemical vector control on the temporal progress of HLB epidemics.

Reduction of inoculum is a strategy that demands a continuous and costly dedication of manpower resources, because every tree must be inspected by well-trained and motivated scouting teams multiple times per year and diseased trees must be removed. Trees with subclinical symptoms remain in the grove after removal of visually symptomatic detected trees (18) but frequent inspections and removals minimize the time that they are available to provide inoculum. It is unknown how much inoculum these early-stageinfected trees (either asymptomatic or with limited symptoms) may contribute to HLB dispersal $(14,15)$. Frequent inspection and tree removal is not always employed by growers because there is a direct and immediate economic loss when a symptomatic but productive tree is eliminated. Additionally, due to the long incubation 
and latency period of HLB, results of roguing would be observed only in the long term and, therefore, do not provide an immediate payback to growers.

Chemical control of the HLB psyllid vectors is perhaps the easiest HLB control strategy for citrus growers because all commercial citrus producers have access to the machinery or management companies that can apply insecticides for psyllid control. However, the additional and frequent insecticide applications required are costly. Although there is much information on the effect of chemical control of various insecticides and programs on psyllid vector population, the effect of this practice on HLB temporal progress remains largely anecdotal and undocumented $(6,15)$. In a recent study in an HLB-endemic region in Vietnam, conventional insecticide practices consisting of fortnightly spraying of contact insecticide or monthly trunk applications of systemic insecticide effectively reduced ACP populations by killing adults and nymphs and by affecting or preventing psyllid reproduction in groves. However, neither of the two insecticide treatments totally prevented transmission of ' $C a$. L. asiaticus' (13).

Therefore, in order to establish an economically sustainable HLB management program based on inoculum reduction and insect vector control, it is important to know the effectiveness of both strategies on the HLB epidemics in regard to the frequency that they are applied and their yearly and multiyear costs. Considering these factors, our main objectives were to assess the effectiveness and importance of both strategies applied within young citrus plots (local management), in different frequencies and combinations, on HLB temporal progress when the plots are surrounded by groves either with or without HLB management (regional management).

\section{Materials and Methods}

Field trials and HLB management within and around the experimental areas. Two field experiments, located approximately $37 \mathrm{~km}$ from each other, were carried out in the central region of Sao Paulo State, Brazil. This is the region most affected by HLB epidemics in Sao Paulo State. Both experiments started with the planting of disease-free nursery plants produced under insect-proof screenhouses.

Experiment 1 (E1) consisted of a new grove of 'Valencia Americana' sweet orange (Citrus sinensis (L.) Osbeck) grafted on 'Swingle' citrumelo (Poncirus trifoliata (L.) Raf. $\times$ C. paradise Macf.), planted in October 2005, in the middle of a large citrus farm. The planting was surrounded to the north by natural forest and to the east, south, and west by many neighboring citrus blocks within an approximately $1.8-\mathrm{km}$ radius. The surrounding blocks were under a rigorous HLB control based on insecticide applications (4 to 5 per year in 2004, 2005, and 2006; 7 per year in 2007; and 12 to 14 per year in 2008, 2009, and 2010) and inspection and removal of HLBsymptomatic trees (three to four times per year) since July 2004. Citrus plantings without HLB management were more than $1.8 \mathrm{~km}$ distant from the experimental area to the southwest and south (Fig. 1A). The density (expressed as a proportion of the total area) of citrus groves with and without HLB management within a $2-\mathrm{km}$ radius was 0.556 and 0.002 , respectively. This experimental area was divided into 27 plots of 0.79 ha, each with 528 trees (16 rows with 33 plants) arranged in a 6.0-by-2.5-m spacing. The experiment consisted of a completely randomized block design arranged in three-by-three factorial scheme with three replications for each treatment. The factor "local inoculum reduction" had three levels: removal of symptomatic trees every 28, 56, or 112 days; and the factor "local vector control" had three levels: no psyllid control, psyllid control program A, or psyllid control program B. For plots with psyllid control programs, the following strategies were applied: during the rainy season, starting in November or December, trees received two systemic insecticide applications with a 56-day interval between applications, consisted of alternating aldicarb via soil (Temik $150 \mathrm{G}$, at $25 \mathrm{~g} \mathrm{~m}^{-1}$ tree ${ }^{-1}$; Bayer CropScience) and thiamethoxam via drench (Actara $250 \mathrm{WG}$ at $1.25 \mathrm{~g}$ $\mathrm{m}^{-1}$ tree $^{-1}$; Syngenta); and, from April to November, insecticide sprays were applied every 28 days for psyllid control program A and every 14 days for psyllid control program B, alternating among imidachloprid (Provado $200 \mathrm{SC}$ at $0.2 \mathrm{ml} \mathrm{liter}^{-1}$; Bayer CropScience), dimethoate (Dimetoato $500 \mathrm{EC}$ at $1.0 \mathrm{ml} \mathrm{liter}^{-1}$; Nortox $\mathrm{SA}$ ), and lambda-cyhalothrin (Karate Zeon $50 \mathrm{CS}$ at $0.1 \mathrm{ml} \mathrm{liter}^{-1}$; Syngenta).

Experiment 2 (E2) consisted of a new grove of 'Valencia' sweet orange $(C$. sinensis (L.) Osbeck) grafted on 'Rangpur' lime $(C$. limonia Osbeck) planted in April 2006 in a small farm immediately surrounded by sugar cane blocks and small citrus blocks. The small citrus blocks were planted at the same time as those blocks within the experiment and with the same vector control program $\mathrm{C}$ as applied in the experimental area. Psyllid control program $\mathrm{C}$ was the same as program B except that lambda-cyhalothrin was replaced by etofenprox (Trebon $100 \mathrm{SC}$ at $0.25 \mathrm{ml} \mathrm{liter}^{-1}$; Sipcam Isagro) for foliar insecticide sprays. For the duration of the experiment, at least 18 highly HLB-affected small citrus blocks existed to the west and 1 to the east within 0.8 to $1.5 \mathrm{~km}$ of the experimental area (Fig. 1B). Management in these external citrus blocks involved neither HLB-affected tree removal nor psyllid control. The density of citrus groves with and without HLB management within a 2-km radius was 0.007 and 0.029 , respectively. This experimental area was divided into 24 plots of

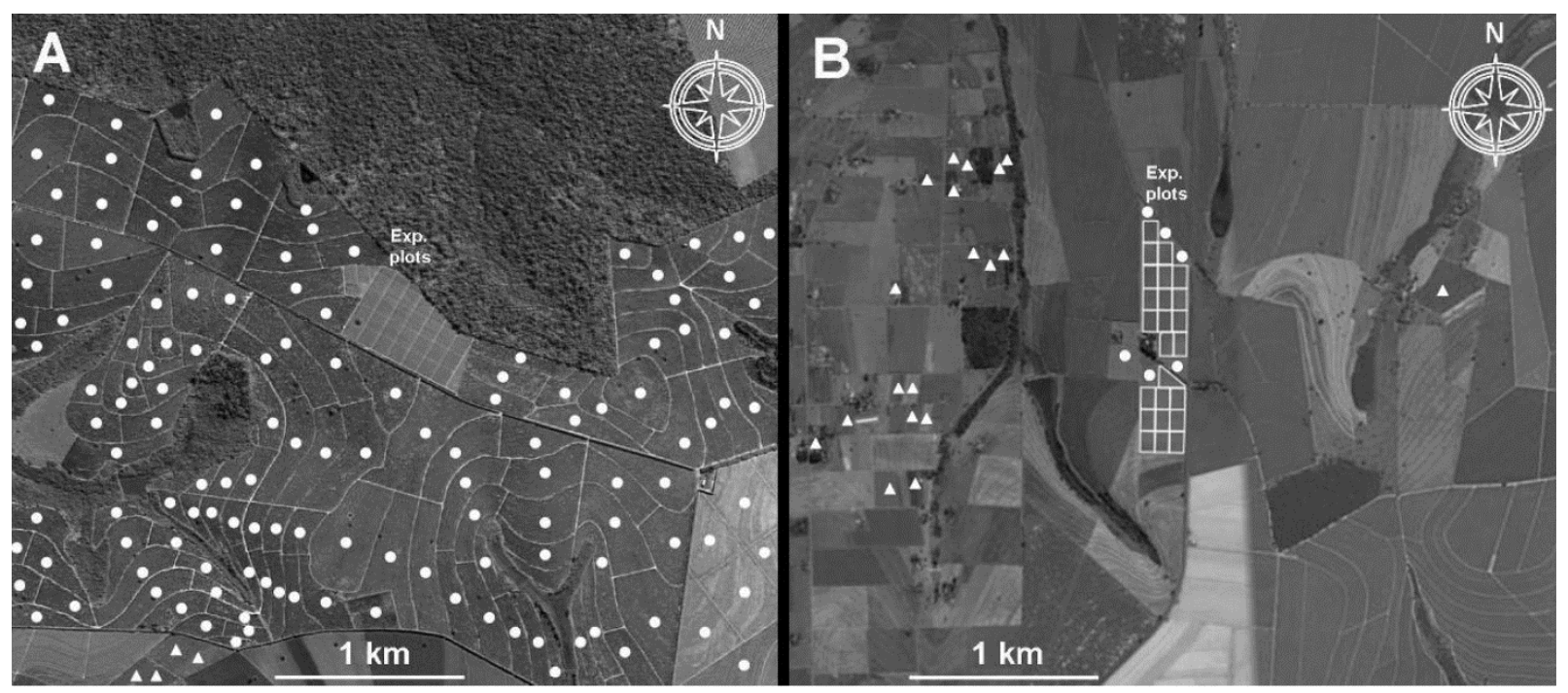

Fig. 1. Aerial view of experimental areas A, E1 and B, E2 and surrounding citrus plantings with (circle) and without (triangle) huanglongbing management based on removal of symptomatic trees and vector control. 
0.98 ha, each with 504 trees (18 rows with 28 plants) arranged in a 6.7-by-2.9-m spacing. The experiment consisted of a completely randomized block design arranged in four-by-two factorial with three replications for each treatment. The factor "local inoculum reduction" had four levels: removal of symptomatic trees every 14 , 28,84 , or 182 days; and the factor "local vector control" had two levels: no psyllid control and psyllid control program C.

Assessments. In both experiments, the populations of ACP, the number of new shoots, the incidence of HLB-symptomatic trees, and the fruit yield were assessed as follows.

$A C P$. In both experiments, psyllid populations were assessed fortnightly from the planting establishment to December 2010. Assessments consisted of counts of adults of D. citri captured on six yellow sticky traps and counts of psyllid adults, nymphs, and eggs present on three shoots of six selected plants distributed in the central area of each plot (plants 6 and 11 of rows 11, 17, and 23 for E1 and plants 7 and 12 of rows 10, 14, and 18 for E2).

New shoots. The presence and number of new shoots (up to 10 $\mathrm{cm}$ in length), preferred plant tissues for ACP feeding and reproduction, were assessed at the same time and in the same plants selected for ACP assessments. Assessments consisted of counts of new shoots in three branches of each tree.

$H L B$-symptomatic trees incidence. HLB incidence was visually assessed monthly in E1 and fortnightly in E2 in each plot. All sus- pect HLB-infected plants were tested by polymerase chain reaction (PCR) according to Teixeira et al. (22) for the presence of ' $\mathrm{Ca}$. L. asiaticus' and/or ' $\mathrm{Ca}$. L. americanus'. For each plot, all adult psyllids caught on yellow sticky traps were divided in groups of one to eight individuals and tested by real time PCR for the presence of ' $\mathrm{Ca}$. Liberibacter' spp. according to Li et al. (19).

Fruit yield. All trees from each plot of each experiment were harvested in 2008, 2009, and 2010. In E1, the early variety Valencia Americana was harvested between May and July and, in E2, the late variety Valencia was harvested between October and December.

Data analysis. For each treatment in each experiment, the following variables were calculated: (i) mean number of days from establishment to detection of the first HLB-symptomatic tree, (ii) mean number of ACP adults per yellow sticky trap per assessment, (iii) mean number of ACP adults per shoot per assessment, (iv) mean number of ACP nymphs per shoot per assessment, (v) mean number of ACP eggs per shoot per assessment, (vi) mean proportion of bacterialiferous psyllids, (vii) mean annual disease progress rate, (viii) mean cumulative incidence of HLB-symptomatic plants $\left(y_{f}\right.$, proportion), and (ix) mean cumulative fruit yield (in tons per hectare). The proportion of bacterialiferous psyllids in these groups was calculated by its maximum-likelihood estimator, $P^{*}$, with a confidence interval calculated according to Monestier and Labonne

Table 1. Average of observed Asian citrus psyllid population (ACP), percentage of bacterialiferous ACP, days after planting to detect the first huanglongbing (HLB)-symptomatic tree, HLB annual progress rate, HLB cumulative incidence, and cumulative yield for each treatment of experiment $1^{\mathrm{s}}$

\begin{tabular}{|c|c|c|c|c|c|c|c|c|c|}
\hline \multirow[b]{2}{*}{ Local treatments } & \multicolumn{5}{|c|}{ ACP population } & \multicolumn{3}{|c|}{ HLB } & \multirow[b]{2}{*}{ Yield $^{2}$} \\
\hline & Adults $^{t}$ & Adults $^{\mathrm{u}}$ & Nymphs ${ }^{\mathrm{u}}$ & Eggs $^{u}$ & Bacter. $^{\mathbf{v}}$ & Beginning $^{w}$ & Rate $^{x}$ & Incidence $^{\mathrm{y}}$ & \\
\hline \multicolumn{10}{|l|}{ Inoculum reduction } \\
\hline Every 28 days & $0.0966 \mathrm{a}$ & $0.0022 \mathrm{a}$ & $0.0000 \mathrm{a}$ & $0.0001 \mathrm{a}$ & $1.4 \mathrm{a}$ & $941.7 \mathrm{a}$ & $1.502 \mathrm{a}$ & $6.06 \mathrm{a}$ & $63.2 \mathrm{a}$ \\
\hline Every 56 days & $0.0878 \mathrm{a}$ & $0.0016 \mathrm{a}$ & $0.0000 \mathrm{a}$ & $0.0001 \mathrm{a}$ & $1.2 \mathrm{a}$ & $832.4 \mathrm{a}$ & $1.154 \mathrm{a}$ & $4.94 \mathrm{a}$ & $54.8 \mathrm{a}$ \\
\hline Every 112 days & $0.1044 \mathrm{a}$ & $0.0019 \mathrm{a}$ & $0.0001 \mathrm{a}$ & $0.0007 \mathrm{a}$ & $1.7 \mathrm{a}$ & $885.5 \mathrm{a}$ & $1.299 \mathrm{a}$ & $6.13 \mathrm{a}$ & $56.3 \mathrm{a}$ \\
\hline \multicolumn{10}{|l|}{ Vector control } \\
\hline No control & $0.1213 \mathrm{a}$ & $0.0053 \mathrm{a}$ & $0.0002 \mathrm{a}$ & $0.0014 \mathrm{a}$ & $1.5 \mathrm{a}$ & $885.4 \mathrm{a}$ & $1.525 \mathrm{a}$ & $6.22 \mathrm{a}$ & $53.7 \mathrm{a}$ \\
\hline Program A & $0.0792 \mathrm{~b}$ & $0.0006 \mathrm{~b}$ & $0.0000 \mathrm{a}$ & $0.0000 \mathrm{a}$ & $1.1 \mathrm{a}$ & $876.3 \mathrm{a}$ & $1.198 \mathrm{a}$ & $6.33 \mathrm{a}$ & $59.1 \mathrm{a}$ \\
\hline Program B & $0.0893 \mathrm{ab}$ & $0.0012 \mathrm{~b}$ & $0.0000 \mathrm{a}$ & $0.0001 \mathrm{a}$ & $1.5 \mathrm{a}$ & 897.9 a & $1.231 \mathrm{a}$ & $4.59 \mathrm{a}$ & $61.5 \mathrm{a}$ \\
\hline
\end{tabular}

$\mathrm{s}$ Values within columns followed by the same letter are not different as determined using the Tukey test $(P>0.05)$.

${ }^{\mathrm{t}}$ Average number of ACP adults per yellow sticky trap per assessment (square root transformations of original data were performed for statistical analysis but arithmetic means are shown in the table).

"Average number of ACP adults, nymphs, or eggs per shoot per assessment (square root transformations of original data were performed for statistical analysis but arithmetic means are shown in the table).

v Bacterialiferous: average percentage ACP adults caught on yellow sticky traps with 'Candidatus Liberibacter asiaticus'.

${ }^{\mathrm{w}}$ Average number of days after planting to detection of the first HLB-symptomatic tree.

$\mathrm{x}$ Average annual HLB progress rate estimated by the logistic model (symptomatic trees per symptomatic trees per year).

y Average cumulative incidence of HLB-symptomatic trees (\%).

${ }^{\mathrm{z}}$ Average cumulative yield (tons/ha) over the first 3 years $(2008,2009$, and 2010).

Table 2. Average of observed Asian citrus psyllid population (ACP), percentage of bacterialiferous ACP, days after planting to detect the first huanglongbing (HLB)-symptomatic tree, HLB annual progress rate, HLB cumulative incidence, and cumulative yield for each treatment of experiment $2^{\mathrm{s}}$

\begin{tabular}{|c|c|c|c|c|c|c|c|c|c|}
\hline \multirow[b]{2}{*}{ Local treatments } & \multicolumn{5}{|c|}{ ACP population } & \multicolumn{3}{|c|}{ HLB } & \multirow[b]{2}{*}{ Yield $^{\mathrm{z}}$} \\
\hline & Adults $^{t}$ & Adults $^{\mathrm{u}}$ & Nymphs ${ }^{u}$ & Eggs $^{u}$ & Bacter. $^{v}$ & Beginning $^{w}$ & Rate $^{x}$ & Incidence $^{y}$ & \\
\hline \multicolumn{10}{|l|}{ Inoculum reduction } \\
\hline Every 14 days & $0.3048 \mathrm{a}$ & $0.0186 \mathrm{a}$ & $0.0177 \mathrm{a}$ & $0.0283 \mathrm{a}$ & $8.7 \mathrm{ab}$ & $569.7 \mathrm{a}$ & $2.727 \mathrm{a}$ & $70.32 \mathrm{a}$ & $12.9 \mathrm{a}$ \\
\hline Every 28 days & $0.1594 \mathrm{a}$ & $0.0103 \mathrm{a}$ & $0.0130 \mathrm{a}$ & $0.0184 \mathrm{a}$ & $13.3 \mathrm{ab}$ & $590.8 \mathrm{a}$ & $2.751 \mathrm{a}$ & $63.32 \mathrm{a}$ & $15.7 \mathrm{a}$ \\
\hline Every 84 days & $0.2634 \mathrm{a}$ & $0.0203 \mathrm{a}$ & $0.0250 \mathrm{a}$ & $0.0284 \mathrm{a}$ & $4.4 \mathrm{~b}$ & $632.7 \mathrm{a}$ & $2.499 \mathrm{a}$ & $61.27 \mathrm{a}$ & $15.6 \mathrm{a}$ \\
\hline Every 182 days & $0.2173 \mathrm{a}$ & $0.0163 \mathrm{a}$ & $0.0287 \mathrm{a}$ & $0.0301 \mathrm{a}$ & $14.2 \mathrm{a}$ & $556.2 \mathrm{a}$ & $2.710 \mathrm{a}$ & $65.10 \mathrm{a}$ & $16.9 \mathrm{a}$ \\
\hline \multicolumn{10}{|l|}{ Vector control } \\
\hline No control & $0.4595 \mathrm{a}$ & $0.0387 \mathrm{a}$ & $0.0653 \mathrm{a}$ & $0.0723 \mathrm{a}$ & $9.8 \mathrm{a}$ & $547.6 \mathrm{a}$ & $2.807 \mathrm{a}$ & $76.86 \mathrm{a}$ & $9.1 \mathrm{a}$ \\
\hline Program C & $0.0826 \mathrm{~b}$ & $0.0033 \mathrm{~b}$ & $0.0010 \mathrm{~b}$ & $0.0029 \mathrm{~b}$ & $10.5 \mathrm{a}$ & $627.1 \mathrm{a}$ & $2.536 \mathrm{a}$ & $53.14 \mathrm{~b}$ & $21.3 \mathrm{~b}$ \\
\hline
\end{tabular}

s Values within columns followed by the same letter are not different as determined using the Tukey test $(P>0.05)$.

${ }^{t}$ Average number of ACP adults per yellow sticky trap per assessment (square root transformations of original data were performed for statistical analysis but arithmetic means are shown in the table).

" Average number of ACP adults, nymphs, or eggs per shoot per assessment (square root transformations of original data were performed for statistical analysis but arithmetic means are shown in the table).

v Bacterialiferous: average percentage ACP adults caught on yellow sticky traps with 'Candidatus Liberibacter asiaticus'.

${ }^{w}$ Average number of days after planting to detection of the first HLB-symptomatic tree.

${ }^{x}$ Average annual HLB progress rate estimated by the logistic model (symptomatic trees per symptomatic trees per year).

y Average cumulative incidence of HLB-symptomatic trees (\%).

${ }^{\mathrm{z}}$ Average cumulative yield (tons/ha) over the first 3 years $(2008,2009$, and 2010). 
(21): $P^{*}=1-(1-R / N)^{1 / i}$, where $R$ is the number of infected psyllid groups, $N$ is the total number of tested psyllid groups, and $i$ is the number of insects per group. The annual disease progress rate $(r)$ was estimated by fitting the logistic model $(y=1 /\{1+\exp [-(B$ $+r t)]\}$ ) to cumulative data of HLB-symptomatic plants cumulative incidence ( $y$, proportion) as a function of time ( $t$, years) according to Campbell and Madden (8). For each variable, the mean comparisons for treatments were done using Tukey's test at $P=0.05$.

The average number of new shoots per branch per tree per assessment, the percentage of assessments with the presence of new shoots, and the standardized area under new shoots progress curve, calculated by trapezoidal integration (8), for E1 and E2 were compared by $t$ test at $P=0.05$.

The effects of HLB management in the surrounding areas on ACP population and HLB epidemics were measured by comparing the same variables of E1 and E2 for plots without psyllid control and for plots with fortnightly vector control programs using a $t$ test at $P=0.05$ (using data from across all of the inoculum reduction frequencies). Additionally, to verify the effect of HLB management in the surrounding areas on the dynamics of psyllid populations, the number of adult psyllids caught per yellow sticky trap per assessment in all plots without psyllid control was plotted as a function of time. Then the rate of total number of adult psyllids caught per yellow sticky trap in the last four 12-month intervals from the beginning of November 2006 to the end of October $2010(\mathrm{~d} y / \mathrm{d} t)$ was calculated for each plot and the change in the rate (i.e., accel- eration/deceleration) (16) of adult psyllid populations over time $[(\mathrm{d} y / \mathrm{d} t) / \mathrm{d} t]$ was estimated for each plot as the angular coefficient of the linear regression between the total number of adult psyllids caught per yellow sticky trap in a 12-month interval $(y)$ and time in years $(t)$.

\section{Results}

For both experiments (E1 and E2), no differences among local inoculum reduction treatments were observed relative to the average number of $D$. citri adults, nymphs, and egg populations, days after planting for the first HLB-symptomatic tree onset, disease progress rates, final HLB-symptomatic tree incidences, and cumulative fruit yield (Tables 1 and 2). For E1, no difference was observed on percentage of bacterialiferous psyllids among local inoculum reduction treatments (Table 1). However, for E2, the average percentage of bacterialiferous psyllids in plots with local inoculum reduction every 182 days was significantly higher than in plots with local inoculum reduction every 84 days; however, neither of those intervals differed from the means for bacterialiferous psyllids in plots with local inoculum reduction every 14 and 28 days (Table 2). Also, the curves showing mean cumulative disease incidence (Fig. 2A and B) and the curves showing mean annual productivity (Fig. 3A and B) for local inoculum reduction treatments did not differ within each experiment.

Considering local vector control in E1, significant differences were observed only for the means related to adult psyllid popula-
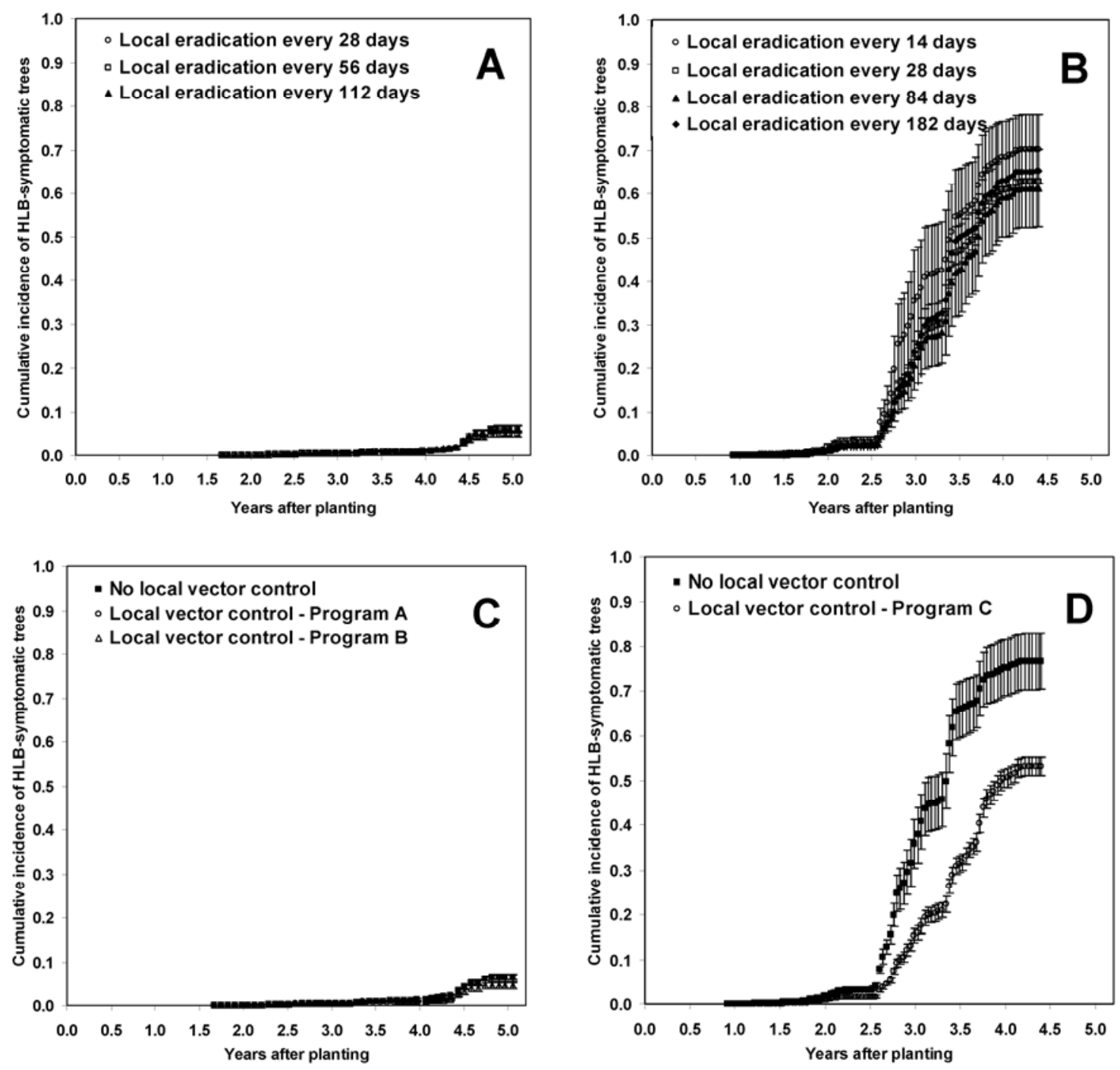

Fig. 2. Progress curves of cumulative huanglongbing-symptomatic trees incidence (proportion) in relation to the $\mathbf{A}$ and $\mathbf{B}$, local inoculum reduction (i.e., tree removal) and $\mathbf{C}$ and $\mathbf{D}$, local insect vector control treatments in experiments $\mathbf{A}$ and $\mathbf{C}, 1$ and $\mathbf{B}$ and $\mathbf{D}, 2$. Bars represent the standard errors of mean. 
tions on traps and shoots, with higher populations in the plots with no insect vector control compared with plots treated with insecticides (Table 1). Variables related to disease also showed no differences among local vector control treatments in E1 (Table 1; Fig. 2C) or for annual and cumulative fruit yield (Table 1; Fig. 3C). In E1, the annual productivity of all plots increased over time, as expected for young citrus plantings (Fig. 3C).

In E2, all variables related to $D$. citri population were higher in plots without local vector control compared with plots under insecticide applications, except the percentage of bacterialiferous adult psyllids (Table 2). The local vector control program $\mathrm{C}$ reduced $82,91,98$, and $96 \%$ of the populations of $D$. citri adults on traps and adults, nymphs, and eggs on shoots, respectively. The local insect vector control treatments of E2 did not affect the initiation date of epidemics or the disease progress rate (Table 2) but plots with no ACP control had cumulative HLB incidences at the end of assessments that were $31 \%$ higher than plots with local ACP control program C (Table 2; Fig. 2D), and that resulted in a significant $57 \%$ reduction in cumulative fruit yield (Table 2). Following the second harvest in 2009, the average annual productivity in plots with no ACP control was significantly lower than in plots with local ACP control program $\mathrm{C}$, and the difference increased in the third harvest in 2010 (Fig. 3D). In E2, the annual productivity of all plots, including plots with local ACP control, did not increase over time as expected for young citrus plantings (Fig. 3D).
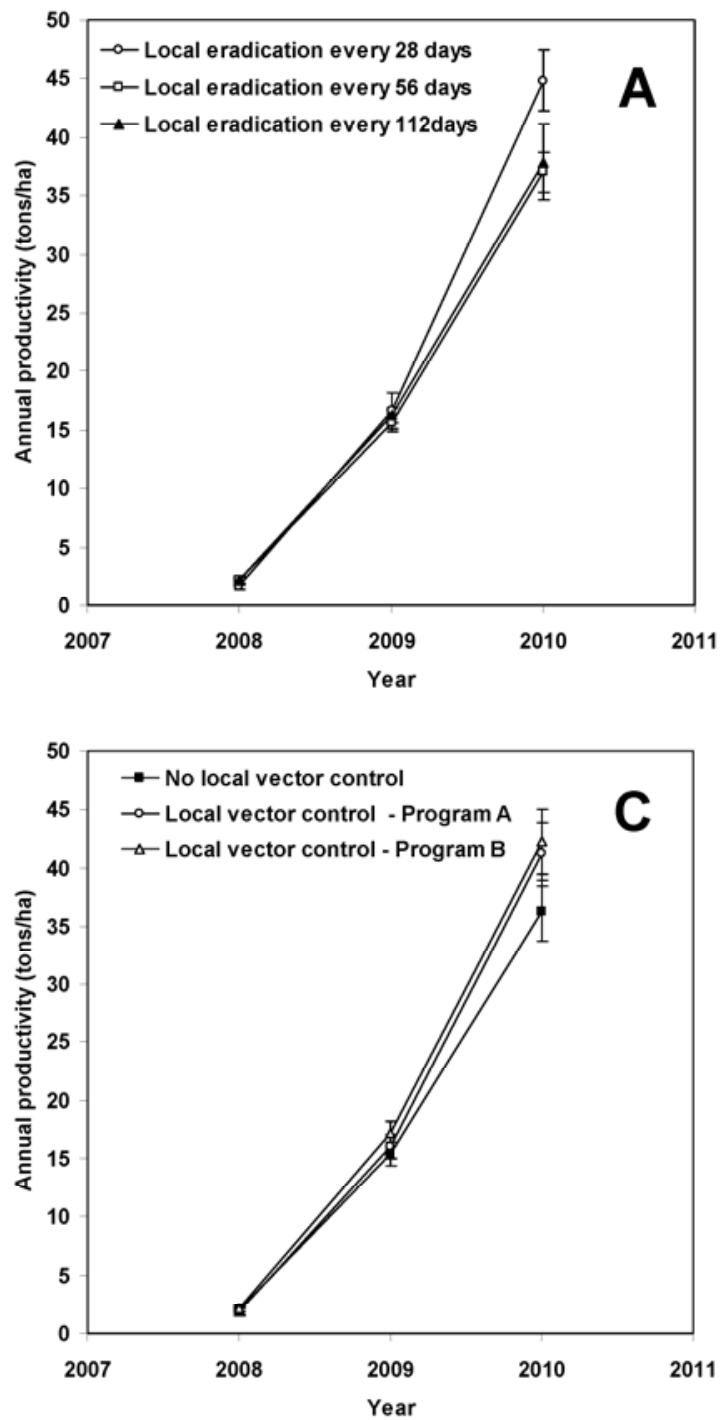

The dynamics of vegetative flushes in E1 and E2 are shown in Figure 4. It was observed that trees in E1 had more new shoots than in E2 (average of 0.63 new shoots per branch per assessment in $\mathrm{E} 1$ and 0.55 in E2, $P=0.000006$ ), higher standardized area under new shoots progress curve than in E2 (average of 0.62 new shoots per branch.day per day in E1 and 0.55 in E2, $P=0.000326$ ), and the same percentage of assessments with the presence of new

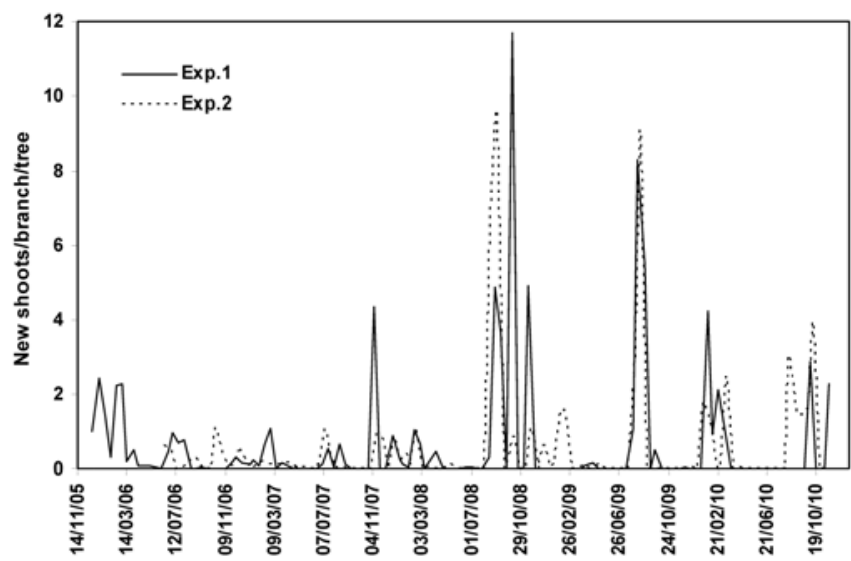

Fig. 4. Temporal dynamics of new shoot per branch in experimental areas E1 and E2.
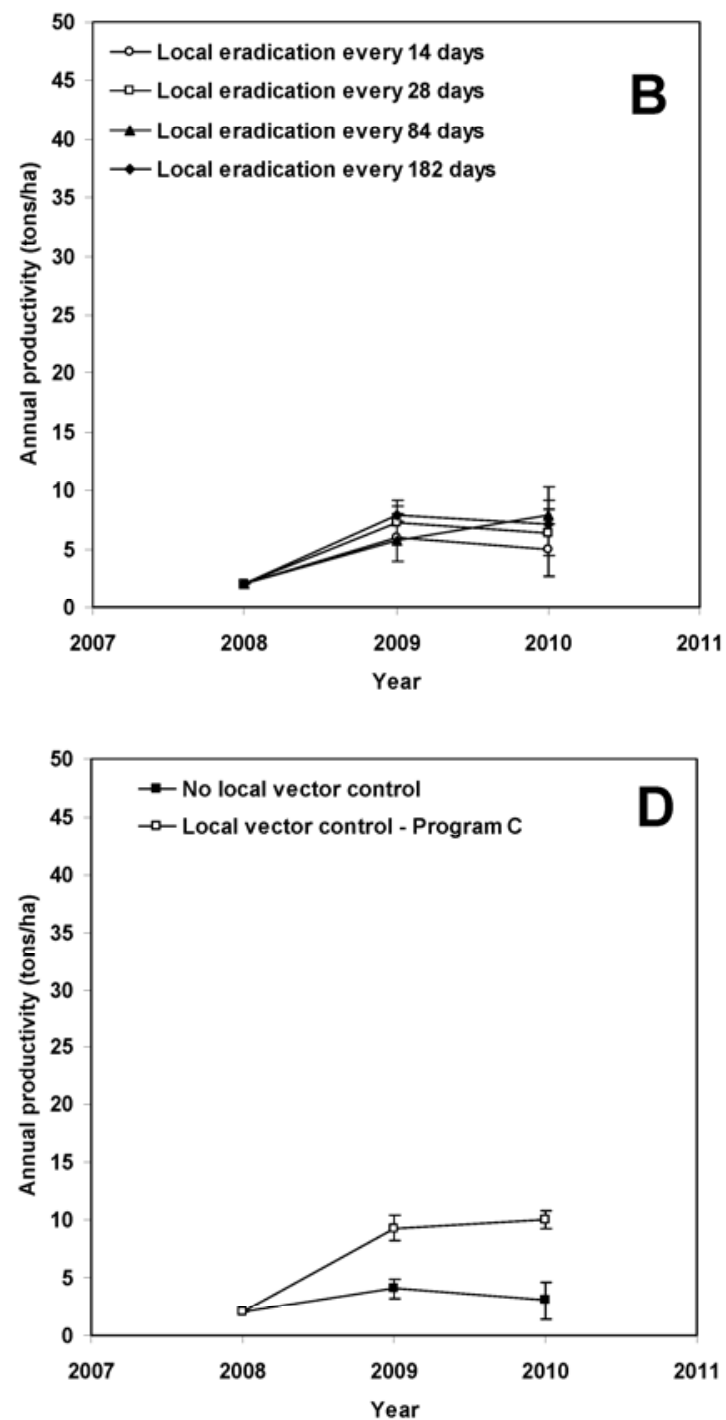

Fig. 3. Progress of the average annual productivity, in tons per hectare, from plots of experiments $\mathbf{A}$ and $\mathbf{C}, 1$ and $\mathbf{B}$ and $\mathbf{D}, 2$ relative to treatments of $\mathbf{A}$ and $\mathbf{B}$, local inoculum reduction and $\mathbf{C}$ and $\mathbf{D}$, local insect vector control. Bars represent the standard error of the mean. 
shoots (average of $34.0 \%$ of assessments with new shoots in E1 and $34.4 \%$ in $\mathrm{E} 2, P=0.536111$ ).

Comparing the results of E1 with E2 relative to plots with and without fortnightly ACP control programs, all except two variables were higher in E2 compared with E1. Adult psyllids captured on traps were similar in both experiments and the time from planting to detection of the first HLB-symptomatic tree was higher in E1 (Table 3). In plots without ACP control, populations of adults, nymphs, and eggs observed on shoots were 64, 100, and $96 \%$ lower, respectively, in E1 compared with E2. In plots with fortnightly ACP control, populations of adults on traps and of adults, nymphs, and eggs observed on shoots were $81,86,100$, and $98 \%$ reduced, respectively, in E1 compared with E2. In plots of E2 without ACP control, the numbers of adult psyllids captured on the traps remained approximately at the same level across all years, and the change in these rates over time ranged between -3.37 and 17.83 per year, suggesting that there was no general trend in acceleration or deceleration of adult psyllid populations over time (Figs. 5B and 6B). Nevertheless, in the plots without ACP control in E1, the adult psyllid populations declined over years in all plots, with deceleration rates of -1.30 to -4.33 per year (Figs. $5 \mathrm{~A}$ and 6A). In E2, the average percentage of bacterialiferous psyllids was approximately $10 \%$ in plots with ACP control as well as in plots without control whereas, in E1, it was nearly $1 \%$ (Table 3 ). As a consequence of the smaller population of ACP and smaller population of bacterialiferous psyllids in E1, the HLB epidemics in E1 began 9 to 11 months later and had 46 to $51 \%$ lower logistic progress rates compared with E2, resulting in 91 to $92 \%$ less final HLB incidence in E1 compared with E2 plots regardless of ACP control program (Table 3).

\section{Discussion}

A recently published case study on HLB management practices adopted in Sao Paulo State by Brazilian citrus growers pointed out that HLB epidemics can be suppressed if (i) inoculum removal and insect vector control are initiated at low HLB-incidence, (ii) the trees are older than 5 years, (iii) the farm is large (several hundred hectares), (iv) HLB-management is practiced on all citrus farms within $4 \mathrm{~km}$, and (v) the farm is in a region with an overall low HLB incidence (1). In the absence of any one of those characteristics, local HLB management needs to be tightened. Even with tighter local management, HLB will be difficult or impossible to control. The last four characteristics necessary for the success of HLB management are related to the management of this disease regionally (i.e., area-wide management). The present work experimentally demonstrated for the first time the ineffectiveness of traditional recommended practices to control HLB when disease inoculum sources and ACP population were controlled only at the local scale (E2). It also demonstrated the effectiveness of area-wide management of HLB by reduction of inoculum sources and ACP population resulting in reduction of disease epidemics (E1).

The duration of this experiment may have been too short to document the benefits of local inoculum reduction treatments because of long incubation period (6 to 12 months) (5) and a relatively short period for treatments after the first symptomatic tree was detected (32 months in E1 and 36 months in E2). Also, it is important to note that, in both experiments, independent of inoculum removal frequency, all inspections to detect symptomatic trees were done at the same monthly (in E1) and fortnightly (in E2) frequency. These inspection frequencies significantly reduced symptomatic tree escapes in all plots when compared with longer intervals between inspections. For example, in E2, 12 inspections were done between two tree removal cycles during the 6-month interval of treatment. This high inspection frequency resulted in a higher final number of trees detected and eliminated compared with only one inspection every 6 months. On average, approximately $48 \%$ of the HLB-symptomatic trees present in a citrus block are not detected after an inspection performed by one walking team of inspectors. The probability of detecting all symptomatic trees of a block with only one inspection is only $29 \%(2,3)$.

Disease suppression will be achieved only if tree removals offset or exceed the number of newly infected trees (14). If the number of tree removals is not sufficient to offset new infections, the number of infected trees will not decrease in a timely manner, and tree removal as a control strategy will fail (12).

The ineffectiveness of the different treatments to achieve local inoculum reduction in both experiments indicates that, at the experimental spatial scale of these plots (approximately 1 ha in area), HLB epidemic progress depends on infections introduced by immigrant bacterialiferous psyllids coming from external, poorly managed orchards rather than from infections by psyllids that acquired the pathogen from within-grove inoculum sources.

Due to the constant movement of $D$. citri adults among citrus groves and other alternative hosts (4) and their capacity to spread at long distances $(15,17)$, even citrus plantings with an intensive ACP control program are constantly reinfested and subject to new primary infections. Thus, the higher the psyllid density in surrounding plantings, the higher the migratory flux of adult psyllids to the healthy plantings under good management, and the higher the chances for new infections to occur, especially when psyllids are bacterialiferous as in E2.

Table 3. Comparison of experiments 1 and 2 average of observed Asian citrus psyllid population (ACP), percentage of bacterialiferous ACP, days after planting to detect the first huanglongbing (HLB)-symptomatic tree, HLB annual progress rate, and cumulative incidence between plots without and with fortnightly ACP control program ${ }^{t}$

\begin{tabular}{|c|c|c|c|c|c|c|c|c|}
\hline \multirow[b]{2}{*}{ Control, experiment } & \multicolumn{5}{|c|}{ ACP population } & \multicolumn{3}{|c|}{ HLB } \\
\hline & Adults ${ }^{u}$ & Adults $^{v}$ & Nymphs $^{v}$ & Eggs $^{v}$ & Bacterialiferous $^{w}$ & Beginning $^{x}$ & Rate $^{y}$ & Incidence $^{\mathrm{z}}$ \\
\hline \multicolumn{9}{|l|}{ With control } \\
\hline Experiment 1 & 0.0893 & 0.0012 & 0.0000 & 0.0001 & 1.5 & 897.9 & 1.231 & 4.59 \\
\hline Experiment 2 & $0.0826^{\mathrm{ns}}$ & $0.0033^{*}$ & $0.0010 *$ & $0.0029 *$ & $10.5 * *$ & $627.1 * *$ & $2.536 * *$ & $53.14 * *$ \\
\hline$P$ value & 0.660 & 0.049 & 0.024 & 0.041 & 0.000 & 0.001 & 0.000 & 0.000 \\
\hline \multicolumn{9}{|l|}{ Without control } \\
\hline Experiment 1 & 0.1213 & 0.0053 & 0.0002 & 0.0014 & 1.5 & 885.4 & 1.525 & 6.22 \\
\hline Experiment 2 & $0.4595 * *$ & $0.0387 * *$ & $0.0653 * *$ & $0.0723 * *$ & $9.8^{* *}$ & $547.6^{* *}$ & $2.807 * *$ & $76.86^{* *}$ \\
\hline$P$ value & 0.001 & 0.000 & 0.000 & 0.000 & 0.000 & 0.000 & 0.000 & 0.000 \\
\hline
\end{tabular}

${ }_{\mathrm{t}}$ Value of experiment 2 differed from value of experiment 1 by $t$ test at 1 and $5 \%$ significance $\left({ }^{*}\right.$ and ${ }^{* *}$, respectively); ns indicates that values did not differ by $t$ test $(P>0.05)$.

"Average number of ACP adults per yellow sticky trap per assessment (square root transformations of original data were performed for statistical analysis but arithmetic means are shown in the table).

${ }^{\vee}$ Average number of ACP adults, nymphs, or eggs per shoot per assessment (square root transformations of original data were performed for statistical analysis but arithmetic means are shown in the table).

w Average percentage ACP adults caught on yellow sticky traps with 'Candidatus Liberibacter asiaticus'.

${ }^{x}$ Epidemics beginning: average number of days after planting to detect the first HLB-symptomatic tree.

${ }^{y}$ Average annual HLB progress rate estimated by the logistic model (symptomatic trees per symptomatic trees per year).

${ }^{\mathrm{z}}$ Average cumulative incidence of HLB-symptomatic trees (\%). 
Although the frequent insecticide applications resulted in efficient reduction of psyllid populations $(>80 \%)$, local vector control program $\mathrm{C}$ had a limited effect on the disease progress rate and only decreased final disease incidence by $31 \%$ compared with plots receiving no psyllid control. This was expected based on prior knowledge of the spread of virus diseases that are vector transmitted. According to Broadbent (7), "applying insecticides to crops has, more often than not, failed to decrease the incidence of virus diseases in the sprayed crops (...) even though field inspections of the crops indicated that the insecticide has controlled the specific insect vector". This occurs because immigrant psyllids that are bacterialiferous can, in many cases, transmit the bacteria to trees before they are killed by insecticides.

The suppression of disease progress was not as pronounced as that described by Gatineau et al. (13) in an HLB-endemic region in Vietnam. In Vietnam, with conventional insecticide practices of (i) fortnightly spraying of contact insecticide or (ii) monthly trunk applications of systemic insecticide, 2 years after plantation, the ACP adult and nymph populations were reduced by 93.5 and $75.2 \%$, and 99.1 and $100.0 \%$, respectively, while the disease incidence was reduced by 20.7 and $74.5 \%$, respectively, in relation to plots without ACP control. In Vietnam, a logistic disease progress model predicted disease prevalence of 0.995 only 3.5 and 4.7 years after planting in plots treated with fenobucard and imidachloprid, respectively.

Considering how the occurrence and abundance of new shoots favored ACP populations, we suggest that trees in E1 favored higher ACP populations than trees in E2 because, even with a similar percentage of assessments with new shoots in both experiments, there were higher numbers of new shoots per branch per assessment in E1 than in E2. This resulted in higher standardized area under new shoots progress curve in E1. Therefore, for a comparison between E1 and E2, there was an expected higher probability
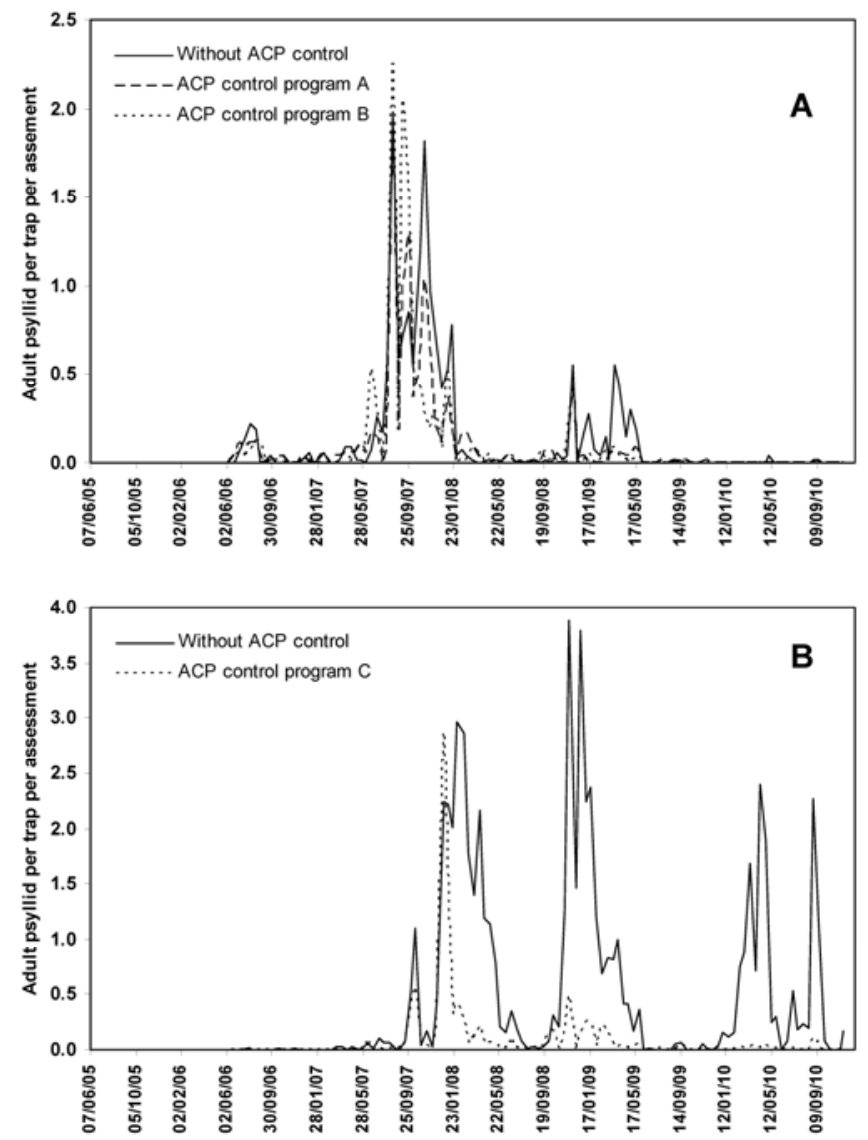

Fig. 5. Temporal dynamics of adult psyllids caught per yellow sticky trap per assessment in plots without and with vector control programs in $\mathbf{A}$, experiment 1 , mean of 9 plots; and B, experiment 2, mean of 12 plots. of new HLB infections in plots with no local vector control in E1 compared with in E2. However, the comparison of E1 and E2 results for plots without psyllid control and for plots with a fortnightly psyllid control program clearly showed the effect of areawide disease inoculum reduction and insect vector management. In $\mathrm{E} 1$, where citrus blocks within a $1.8-\mathrm{km}$ radius practiced HLB inoculum and vector management, the disease epidemic began later and was slower to develop compared with E2, where citrus without HLB management were present at 0.8 to $1.0 \mathrm{~km}$ in distance (Table 3 ). As a consequence, the average final HLB incidence was $91 \%$ lower in E1 plots with and without ACP control compared with E2 plots because the area-wide management reduced vector populations and there were relatively few immigrant psyllids that were bacterialiferous. Even with higher favorability for ACP populations in E1, the average psyllid adult, nymph, and egg populations observed on plant shoots of E2 during all periods studied were always higher compared with E1 plots with or without an ACP control program (Table 3). This effect was also observed for adult psyllids caught on yellow sticky traps in plots without a local vector control program. However, in the case of plots with a vector control program, the adult psyllid populations were similar in both experiments (Table 3). The higher ACP numbers recovered from traps are indicative that the reproduction and immigration of ACP were higher in E2 than in E1, mainly in plots without insecticide applications. The continuous decrease of adult psyllid population in the plots without ACP control in E1 is probably due to ACP control in citrus blocks surrounding the experimental area that reduced the immigrant $\mathrm{ACP}$ population into E1 plots. Even in plots without insect vector control, ACP populations did not increase. This is most likely because, in the absence of new flush on the trees within the plots, adult psyllids emigrated to other citrus plots
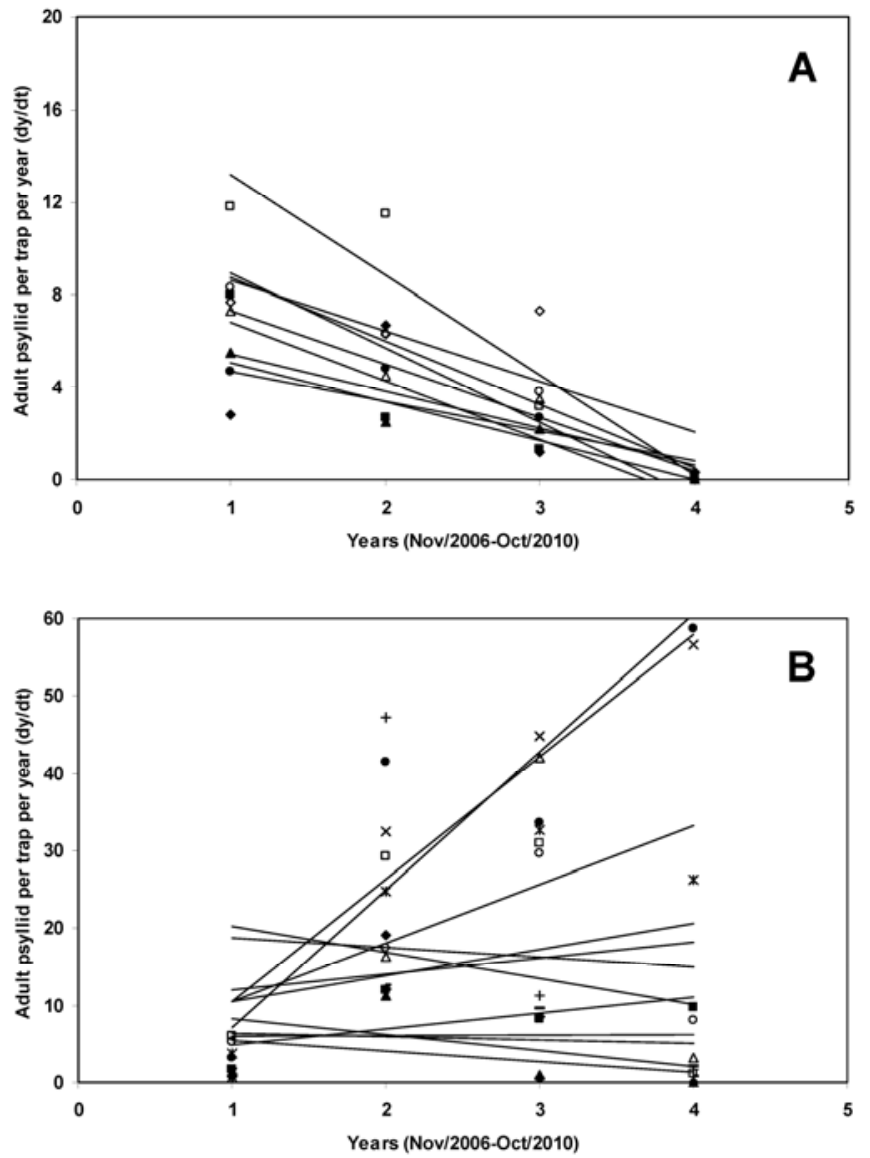

Fig. 6. Change in rate of adult psyllid population (dy/dt) in each plot untreated with insecticide in four 12-month intervals from the beginning of November 2006 to the end of October 2010, and the linear regression [(dy/dt $/ / d t]$, showing the acceleration or deceleration of the adult psyllid population dynamics relative to each replication of $\mathbf{A}$, experiment 1 and $\mathbf{B}$, experiment 2 . 
or blocks looking for trees with new shoots to colonize. Therefore, during each growth cycle, the ACP population in the plots was dependent on reinfestation by immigrant psyllids from external citrus plantings. With frequent application of insecticides on trees of neighboring experimental plots and surrounded citrus plantings, the surrounding ACP population responsible for reinfestation was reduced; whereas, without insecticide application in the area surrounding the experimental plot, as in the case of E2, the reinfestation every growth cycle was continuous. In addition to the reduction of immigrant ACP populations arriving at the experimental area achieved by area-wide application of insecticides, the regional reduction of HLB inoculum played an important role in reducing the number of bacterialiferous psyllids caught on traps. In plots with insecticide applications, the adult population caught on traps was similar in both experiments and the adult population on shoots in E1 was $64 \%$ less than in E2. However, the final HLB incidence was $91 \%$ less, probably because the bacterialiferous psyllid population was also smaller, concomitant with much-reduced inoculum sources.

Another advantage of area-wide HLB management is that lessintensive insect vector control programs (program A in E1) can be equal to or more efficient than a more intensive control program (program $\mathrm{C}$ in E2) in non-area-wide control areas. The efficacy of area-wide control considerably reduces the costs of local HLB management and maintains the expected increase in annual productivity for young citrus plantings. For E2 without area-wide management using fortnightly insecticide applications, the mean incidence of HLB-symptomatic trees at the end of the experiment was $53.1 \%$ and the productivity was the same in the second and third harvests whereas, for E1 with area-wide management, in plots with half the number of foliar insecticide applications and in plots without insecticide application, the HLB incidences were 6.3 and $6.2 \%$, respectively, and the productivity increased significantly from second to third harvest in both treatments.

We conclude that the results of the current study, combined with personal observations in Brazil, the United States, and elsewhere, demonstrate that it is essential for citrus growers to organize and collaborate in order to implement area-wide HLB-management strategies to achieve viable long-term control of HLB. As a direct result of this study, the concept of area-wide management has become the mainstay of HLB control programs in the United States and Brazil. In the United States, the study has motivated citrus producers to come together to form citrus health management areas to attempt to control this disease more effectively on a regional basis. In Brazil, voluntary groups of citrus growers have been formed to control ACP population with three to four coordinated area-wide insecticide applications in defined short periods (1 to 2 weeks). Other Brazilian growers, with the agreement of their neighbors, are supporting the control of ACP populations and infected trees in their neighboring groves to prevent HLB primary infections in their own groves.

\section{Acknowledgments}

This work was financially supported by Fundecitrus, Fapesp (projects 2005/00718-2 and 2007/55013-9), CNPq (project 578049/2008-2), and Citrus Research and Development Foundation (project 8). R. B. Bassanezi, P. T. Yamamoto, L. Amorim, and A. Bergamin Filho have a fellowship from CNPq. We thank N. I. Barrancos from São José Farm; J. L. A. Rodrigues and F. E. A. Tersi from Cambuhy Agrícola Ltd. for the experimental areas; R. A. Santos, P. H. Sperandio, M. A. Jorge, L. Pereira, C. N. Moreira, P. C. G. Basso, A. J. R. da Silva, W. M. Santos, M. A. B. Lima, C. D. Felix, J. C. dos Santos, and A. D. Campagne for field assistance; and G. H. Rodrigues and J. M. Martins for laboratory assistance.

\section{Literature Cited}

1. Belasque Jr., J., Bassanezi, R. B., Yamamoto, P. T., Ayres, A. J., Tachibana, A., Violante, A. R., Tank Jr., A., Di Giorgi, F., Tersi, F. E. A., Menezes, G. M., Dragone, J., Jank Jr., R. H., and Bové, J. M. 2010. Lessons from huanglongbing management in São Paulo State, Brazil. J. Plant Pathol.
92:285-302.

2. Belasque Jr., J., Bergamin Filho, A., Bassanezi, R. B., Barbosa, J. C., Gimenes Fernandes, N., Yamamoto, P. T., Lopes, S. A., Machado, M. A., Leite Jr., R. P., Ayres, A. J., and Massari, C. A. 2009. Base científica para a erradicação de plantas sintomáticas e assintomáticas de huanglongbing (HLB, Greening) visando o controle efetivo da doença. Trop. Plant Pathol. 34:137-145.

3. Belasque Jr., J., Yamamoto, P. T., Miranda, M. P., Bassanezi, R. B., Ayres, A. J., and Bové, J. M. 2010. Controle do huanglongbing no estado de São Paulo, Brasil. Citrus Res. Technol. 31:53-64

4. Boina, D. R., Meyer, W. L., Onagbola, E. O., and Stelinski, L. L. 2009. Quantifying dispersal of Diaphorina citri (Hemiptera: Psyllidae) by immunomarking and potential impact of unmanaged groves on commercial citrus management. Environ. Entomol. 38:1250-1258.

5. Bové, J. M. 2006. Huanglongbing: a destructive, newly emerging, centuryold disease of citrus. J. Plant Pathol. 88:7-37.

6. Brlansky, R. H., and Rogers, M. E. 2007. Citrus huanglongbing: Understanding the vector-pathogen interaction for disease management. APSnet Feature December 2007. Online publication. http://www.apsnet.org/ publications/apsnetfeatures/Pages/Huanglongbing.aspx

7. Broadbent, L. 1957. Insecticidal control of the spread of plant viruses. Annu. Rev. Entomol. 2:339-354

8. Campbell, C. L., and Madden, L. V. 1990. Introduction to Plant Disease Epidemiology. John Wiley \& Sons, New York.

9. Capoor, S. P., Rao, D. G., and Viswanath, S. M. 1967. Diaphorina citri: a vector of the greening disease of citrus in India. Indian J. Agric. Sci. 37:572-576.

10. Coletta-Filho, H. D., Targon, M. L. P. N., Takita, M. A., De Negri, J. D., Pompeu, J., Jr., and Machado, M. A. 2004. First report of causal agent of huanglongbing ("Candidatus Liberibacter asiaticus") in Brazil. Plant Dis. 88:1382.

11. Da Graça, J. V. 1991. Citrus greening disease. Annu. Rev. Phytopathol. 29:109-136.

12. Garnsey, S. M., Gottwald, T. R., and Yokomi, R. K. 1998. Control strategies for citrus tristeza virus. Pages 639-658 in: Plant Virus Disease Control. A. Hadidi, R. K. Khetarpal, and H. Koganezawa, eds. American Phytopathological Society, St. Paul, MN.

13. Gatineau, F., Bonnot, F., Yen, T. T. H., Tuan, D. H., Tuyen, N. D., and Truc, N. T. N. 2010. Effects of imidacloprid and fenobucarb on the dynamics of the psyllid Diaphorina citri Kuwayama and on the incidence of 'Candidatus Liberibacter asiaticus'. Fruits 65:209-220.

14. Gottwald, T. R. 2010. Current epidemiological understanding of citrus huanglongbing. Annu. Rev. Phytopathol. 48:119-139.

15. Gottwald, T. R., da Graça, J. V., and Bassanezi, R. B. 2007. Citrus huanglongbing: the pathogen and its impact. Plant Health Progress. Online publication. doi:10.1094/PHP-2007-0906-01-PubMed RV

16. Gottwald, T. R., Graham, J.H., Irey, M. S., McCollum, T. G., and Wood, B. W. 2012. Inconsequential effect of nutritional treatments on huanglonbing control, fruit quality, bacterial titer and disease progress. Crop Prot. 36:7382 .

17. Gottwald, T. R., Irey, M., Gast, T., Parnell, S., Taylor, E., and Hilf, M. 2010. Spatio-temporal analysis of an HLB epidemic in Florida and implications for future spread. Pages 84-97 in: Proc. 17th Conf. Int. Org. Citrus Virol. Riverside, CA. http://www.ivia.es/iocv/

18. Irey, M. S., Gast, T., and Gottwald, T. R. 2006. Comparison of visual assessment and polymerase chain reaction assay testing to estimate the incidence of the huanglongbing pathogen in commercial Florida citrus. Proc. Fla. State Hortic. Soc. 119:89-93.

19. Li, W., Hartung, J. S., and Levy, L. 2006. Quantitative real time PCR for detection and identification of 'Candidatus Liberibacter' species associated with citrus huanglongbing. J. Microbiol. Methods 66:104-115.

20. Lopes, S. A., Frare, G. F., Bertolini, E., Cambra, M., Fernandes, N. G., Ayres, A. J., Marin, D. R., and Bové, J. M. 2009. Liberibacters associated with citrus huanglongbing in Brazil: 'Candidatus Liberibacter asiaticus' is heat tolerant, 'Ca. L. americanus' is heat sensitive. Plant Dis. 93:257-262.

21. Monestier, P., and Labonne, G. 1981. Etudes des probabilitiés de transmission d'un virus dans le système plantes sources-vecteurs-plantes hôtes. Pages 17-27 in: Biomètrie et Epidémiologie. J. M. Legay and R. Tomasse, eds. INRA, Département de Biomètrie, Paris.

22. Teixeira, D. C., Danet, J. L., Eveillard, S., Martins, E. C., Jesus Jr., W. C., Yamamoto, P. T., Lopes, S. A., Bassanezi, R. B., Ayres, A. J., Saillard, C., and Bové, J. M. 2005. Citrus hanglongbing in São Paulo State, Brazil: PCR detection of the 'Candidatus Liberibacter' species associated with the disease. Mol. Cell. Probes 19:173-179.

23. Yamamoto, P. T., Felippe, M. R., Garbim, L. F., Coelho, J. H. C., Ximenes, N. L., Martins, E. C., Leite, A. P. R., Sousa, M. C., Abrahão, D. P., and Braz, J. D. 2006. Diaphorina citri (Hemiptera: Psyllidae): vector of the bacterium 'Candidatus Liberibacter americanus'. Page 96 in Proc. Huanglongbing Greening Int. Workshop. Fundecitrus, Araraquara. Ribeirão Preto. 